\title{
Relationship between Volatilities of Stock Market and Instruments of Monetary Policy in Vietnam
}

\author{
TRAN PHUONG THAO \\ University of Economics HCMC - tranthao@ueh.edu.vn \\ PHAN CHUNG THUY \\ University of Economics HCMC - phanthuy@ueh.edu.vn
}

\section{ARTICLE INFO ABSTRACT}

Article history:

Received:

Sep. 102014

Received in revised form

Oct. 032014

Accepted:

Dec. 302014

Keywords:

stock exchange, conditional volatility, exchange rate, interest rate, monetary policy.
Volatility of stock exchange and its determinants always attract the attention of investors, researchers and exchange authorities. The research estimates the volatility of Vietnam stock market by measuring the conditional volatility of VN-Index and HNX-Index, and explores the relationship between the volatility of stock exchanges and the volatility of two instruments of monetary policy (overnight rate and exchange rate). Data are collected on a daily basis from Jan. 5, 2006 to March 31, 2014. The research found evidence of volatility of returns through the two indexes and two instruments, but it detected no relationship between the volatilities of these instruments and the stock indexes. Additionally, the research confirms the role of $\mathrm{VN}$ Index as a market maker over HNX-Index. 


\section{Introduction}

Volatility, a term much referred to in the existing literature, denotes the change of a property or random fluctuation of asset prices. The volatility of stock exchange can be measured by various methods, such as the gap between the highest and lowest stock prices in a certain period of time, standard deviation reflecting stock return dispersion, or conditional fluctuations of stock prices in its relation to volatility in the previous terms (Pagan \& Schwert, 1990; Schwert, 1989).

In the recent decades studies of volatility of stock exchange attract undivided attention of researchers in finance and banking, exclusively in emerging market economies. Plenty of theoretical and empirical researches point out that the volatility of a few factors does affect that of stock exchange (Al-Raimony \& El-Nader, 2012; de Santis \& Imrohoroglu, 1997; Hussin et al., 2012). Those frequently mentioned include interest rate, exchange rate, money supply, economic growth, and inflation, etc.

Vietnam stock market, despite being an emerging one, has gradually defined its role in Vietnam's economic development. Up to Dec. 31, 2013, the market recorded a total of 679 stocks and fund certificates (303 and 376 stock codes listed in HOSE and HNX respectively). End-2013 market capitalization reached VND949,000 billion, roughly equivalent to $31 \%$ of GDP (CafeF, 2014).

Vietnam stock market of these impressive attainments has experienced different growth stages, such as 2005-2006 red-hot economic growth, 2007-2009 financial crisis, and 2009-2010 post-crisis (Bui \& Nguyen, 2014). In these stages Vietnam's monetary policy instruments were fairly flexibly employed to adjust critically end-2011 declined interest rate to such a rate of 2007 or manipulate sharp fluctuations of pre-2011 exchange rate for stabilization since 2012 (SBV, 2014). The market's variation over the past period has signified volatility of Vietnam stock market as well as proved an existence of the nexus between such and that of monetary policy instruments.

\section{Theoretical bases on volatility of stock market and instruments of monetary policy}

\subsection{Volatility of stock market}

Volatility is a measure reflecting the change of a property or random fluctuation in asset prices. The volatility of stock market often refers to the change and 
increase/decrease of stock prices by determining the gap between the highest and lowest stock prices in a certain period of time; in other words, the larger the gap, the higher the volatility of stock prices.

Schwert's (1989) research explores standard deviation as the most common measure of volatility of stock returns since it helps determine stock return dispersion, whereas Pagan and Schwert (1990) estimate the volatility by using variance to capture daily changes of stock prices. These are also measures of volatility presented in the studies by Garman and Klass (1980) and Parkinson (1980).

In recent studies by Abdalla and Winker (2012), Xu (1999) and Zakaria and Shamsuddin (2012), volatility of stock market is frequently measured by conditional volatility of the market, to wit: the measured volatility of stock prices counts on not only its current volatility but also that of those previous terms.

Particularly, Engle (1982) and Bollerslev (1986) estimate volatility with conditional variance of a time series by using generalized autoregressive conditional heteroskedasticity (GARCH) model and its extensions to analyze past data. The model is also popularly applied to estimate the variance of a time series with the use of data in the past.

Rousan and Al-Khouri (2005), in addition, measure volatility of Jordan's stock exchange by an application of ARCH and GARCH to daily data from Amman stock exchange between January 1992 and December 2004, figuring out the existence of longlasting volatility in this market which has resulted in inefficient market operations. Meanwhile, Ashok and Sarkar (2006) employ GARCH-extended models to measure volatility of Indian stock exchange. Their results demonstrate that GARCH models function better than other simple ones testing on volatility like past or moving average and that the asymmetric GARCH performs more precise measurement than E-GARCH when volatilities are calculated in groups. Additionally, there remain many other studies on volatility of stock markets as in Pagan and Schwert (1990), de Santis and Imrohoroglu (1997), and Ashok and Sarkar (2006).

\subsection{Instruments of monetary policy}

Monetary policy is a system of measures laid down by the central bank to regulate the national economy with effects on the development of the economy in general and financial market in particular. Various studies indicate that monetary policy of different 
countries is fairly flexibly adjusted, particularly during economic upheavals like financial crisis, war or economic recession, etc. (Cukierman, 2013).

Tang et al. (2013) showcase the impact of monetary policy changes on Chinese monetary and stock markets. Law on the State Bank of Vietnam (SBV) No. 46/2010/QH12 dated June 16, 2010 allows monetary policy to be regulated by such instruments as refinancing, interest rate, exchange rate, required reserves, open market operations, and other tools and measures as the law stands (Vietnam National Assembly, 2010).

Instruments of monetary policy are widely discussed in previous studies, including effects of monetary policy among specific countries (Cachanosky, 2014), monetary policy and operation of commercial banks (Apergis et al., 2012), and monetary policy and stock exchange (Fischbacher et al., 2013; Jansen \& Tsai, 2010; Vithessonthi \& Techarongrojwong, 2013). Particularly, Cukierman (2013) investigates the change in monetary policy in various countries in the world during economic crises, whereas Laopodis (2013) examines the change in American monetary policy through several phases between 1970 and 2005. These studies overally employ the disclosures from companies or data change to explore the roles of instruments of monetary policy.

2.3. Relationship between volatilities of stock market and instruments of monetary policy

Existing research into the determinants of volatility of stock exchange highlights such factors of monetary policy as interest rate, required reserves, money supply, exchange rate, etc. Tang et al. (2013) examine effects of changes in interest rate and required reserves on Chinese stock exchange. Their findings reveal the existence of influence on the stock exchange and especially the fact that bad news exerts more profound impact than good one. Meanwhile, such study by Fernández-Amador et al. (2013) shows that an expansionary monetary policy of the European Central Bank does have effects on liquidity of stock markets as in Germany, France, and Italy.

It appears that a frequently applied method to determine the relationship between monetary policy and stock market is vector autoregressive model (VAR), as in Liljeblom and Stenius (1997), Zakaria and Shamsuddin (2012), and Hussin et al. (2012). For instance, Zakaria and Shamsuddin (2012) employ bi-variate and multivariate VAR Granger causality tests to examine variables and macroeconomic variables as a group affecting Malaysian stock market volatility from January 2000 to June 2012. Using 
VAR, similarly, Al-Raimony and El-Nader (2012) identify the cause of Jordan's market volatility between 1991 and 2010.

Accordingly, volatility has been a subject of existing researches, yet study of conditional volatility has been attracting attention of many researchers, especially when the world economy experienced wide upheavals. Thus, the investigation into stock market volatility and its determinants is crucial in controlling market risks and contributes to economic stability and sustainable development.

\section{Data and methodology}

\subsection{Data}

To examine Vietnam stock market volatility, the paper focuses on daily stock indexes listed on HOSE (VNI) and HNX (HNI). In the meantime, due to the constraints of daily data collection, two instruments of monetary policy employed are overnight rate (ITR) and USD/VND exchange rate (EXR) set by SBV, which are also employed in the studies by Berument (2007), Bhattacharyya and Sensarma (2008), and Fratzscher (2005). The data, including 2,136 observations of each data series, are collected on a daily basis from Thomson Reuters DataStream between Jan. 5, 2006 and March 31, 2014. Logarithm is taken to estimate daily returns $(\mathrm{R})$ of the collected variables based on the following formula:

$\mathrm{R}=\left[\ln \left(\mathrm{Y}_{\mathrm{t}}\right)-\ln \left(\mathrm{Y}_{\mathrm{t}-1}\right)\right] \times 100 \mathrm{R}$

where:

$\mathrm{Y}_{\mathrm{t}}$ : daily collected data of VNI, HNI, ITR and EXR, and

$\mathrm{R}$ : daily returns of the variables and also daily increase rate of ITR and EXP

\subsection{Methodology}

To examine the relationship between volatilities of stock market and instruments of monetary policy, the authors apply two models as follows - (1) One that measures volatility of stock market through returns of the observed variables; and (2) Vector autoregressive model (VAR) to determine the nexus between volatility of stock market returns and of instruments of monetary policy.

3.2.1. Estimation of volatility of stock market through returns of the observed variables 
One commonly employed model, among many others measuring the volatility of certain factors, is GARCH. Proposed in Bollerslev's (1986) study, the model aims at estimating the volatility based on time series data, the details of which are discussed in numerous economic and financial studies, such as Al-Raimony and El-Nader (2012) or Zakaria and Shamsuddin (2012). Generally, GARCH (p,q) is realized through two following stages:

$$
\begin{aligned}
& y_{t}=\delta_{0}+\sum_{i=1}^{k} \delta_{1} y_{1}+\epsilon_{1} \text { with } \varepsilon_{t} \sim N\left(0, \sigma_{t}^{2}\right) \\
& \sigma_{t}^{2}=\varphi+\sum_{i=1}^{q} \alpha_{1} \varepsilon_{t-i}^{2}+\sum_{j=1}^{p} \beta_{j} \sigma_{t-j}^{2} \\
& \text { where: }
\end{aligned}
$$

(2) denotes the equation for the mean in autoregression with lag k, constant $\delta_{0}$, error $\varepsilon$, and variance $\sigma_{t}^{2}$; and

(3) estimates conditional variance, featuring $\operatorname{GARCH}(p, q)$ model where $p$ is the order of $\mathrm{ARCH}$ term, $\mathrm{q}$ is the order of GARCH term, $\sigma_{t}^{2}$ is conditional variance, $\varepsilon_{t-i}^{2}$ reflects volatility of squared error of the past, and $\varphi$ is constant. GARCH is significant when both $\alpha_{1}$ and $\beta_{j}$ are positive and $\alpha_{1}+\beta_{j}<1$.

As mentioned earlier in the review of previous studies on volatility of stock market GARCH $(1,1)$ is widely applied and considered by Gokcan (2000) as appropriate for emerging markets. Thus, to determine volatility as for the case of Vietnam stock market and instruments of monetary policy, the authors employ the same model governed by the following hypotheses:

$\mathrm{H}_{0}$ : No GARCH effects are synonymous with no existence of conditional volatility.

$\mathrm{H}_{1}$ : GARCH effects are synonymous with existence of conditional volatility.

3.2.2. Vector autoregressive model (VAR) for the relationship between volatilities of stock market returns and instruments of monetary policy.

To determine the relationship between the volatilities, the authors conduct stationary test for the data in accordance with the following steps:

Step 1: Examine factor cointegration proposed by Johansen (1988) to examine longterm relationship between these factors to avoid the possibility of spurious correlation.

Step 2: Determine the relationship between the volatilities based on VAR as introduced by Sims (1980) and Engle and Granger (1987). Details of the tests are as below: 


$$
\mathrm{z}_{\mathrm{t}}=\mathrm{c}+\mathrm{A}_{1} \mathrm{z}_{\mathrm{t}-1}+\cdots_{. .}+\mathrm{A}_{\mathrm{p}} \mathrm{z}_{\mathrm{t}-\mathrm{p}}+\mu_{\mathrm{t}}
$$

Equation (4), formulated to test the possibility of factor cointegration, comprises $\mathbf{z}_{t}$ which is (nx1) cointegrating vector of variables at first order or I(0), p (lag of VAR model) and $\mu_{\mathrm{t}}$ (error). Also in the equation, $\lambda_{\text {trace }}$ is employed to determine the possibility of cointegration.

Then, according to achieved results from the cointegration test, the examination of factors affecting volatility of stock market returns is performed based on VAR or VECM models [VAR, guided by equations (5) and (6), is employed in case of no cointegration, or else, VECM, equations (7) and (8)].

VAR model

$$
\begin{aligned}
& \Delta \mathrm{y}_{1 \mathrm{t}}=\mathrm{a}_{\mathrm{o}}+\sum_{\mathrm{i}=1}^{\mathrm{k}} \alpha_{1 \mathrm{i}} \Delta \mathrm{y}_{1 \mathrm{t}-\mathrm{i}}+\sum_{\mathrm{i}=1}^{\mathrm{k}} \alpha_{2 \mathrm{i}} \Delta \mathrm{y}_{2 \mathrm{t}-\mathrm{i}}+\varepsilon_{1 \mathrm{t}} \\
& \Delta \mathrm{y}_{2 \mathrm{t}}=\beta_{\mathrm{o}}+\sum_{\mathrm{i}=1}^{\mathrm{k}} \beta_{1 \mathrm{i}} \Delta \mathrm{y}_{1 \mathrm{t}-\mathrm{i}}+\sum_{\mathrm{i}=1}^{\mathrm{k}} \beta_{2 \mathrm{i}} \Delta \mathrm{y}_{2 \mathrm{t}-\mathrm{i}}+\varepsilon_{2 \mathrm{t}}
\end{aligned}
$$

VECM model

$$
\begin{aligned}
& \Delta \mathrm{y}_{1 \mathrm{t}}=\mathrm{a}_{\mathrm{o}}+\sum_{\mathrm{i}=1}^{\mathrm{k}} \alpha_{1 \mathrm{i}} \Delta \mathrm{y}_{1 \mathrm{t}-\mathrm{i}}+\sum_{\mathrm{i}=1}^{\mathrm{k}} \alpha_{2 \mathrm{i}} \Delta \mathrm{y}_{2 \mathrm{t}-\mathrm{i}}+\emptyset_{\mathrm{y}_{2 \mathrm{t}}} \mathrm{ECT}_{\mathrm{y}_{1, \mathrm{t}-1}}+\varepsilon_{1 \mathrm{t}} \\
& \Delta \mathrm{y}_{2 \mathrm{t}}=\beta_{\mathrm{o}}+\sum_{\mathrm{i}=1}^{\mathrm{k}} \beta_{1 \mathrm{i}} \Delta \mathrm{y}_{1 \mathrm{t}-\mathrm{i}}+\sum_{\mathrm{i}=1}^{\mathrm{k}} \beta_{2 \mathrm{i}} \Delta \mathrm{y}_{2 \mathrm{t}-\mathrm{i}}+\emptyset_{\mathrm{y}_{1 \mathrm{t}}} \mathrm{ECT}_{\mathrm{y}_{2, \mathrm{t}-1}}+\varepsilon_{2 \mathrm{t}}
\end{aligned}
$$

where:

$\Delta y_{1 t}, \Delta y_{2 t}$ : measurement variables of the model, consisting of volatilities of stock indexes and instruments of monetary policy

$\varepsilon_{1 \mathrm{t}}, \varepsilon_{2 \mathrm{t}}:$ errors

$\emptyset_{\mathrm{y}_{2 \mathrm{t}}}, \emptyset_{\mathrm{y}_{1 \mathrm{t}}}$ : constants of cointegrating vector with long-term effects on variables

Both of the models result in the hypothesis that if $\mathrm{H}_{0}: \alpha_{21}=\alpha_{22}=\cdots=\alpha_{2 \mathrm{k}}=0$ is not rejected, then $y_{2 t}$ has no relation to $y_{1 t}$ and if, conversely, $H_{0}: \beta_{21}=\beta_{22}=\cdots=$ $\beta_{21}=0$ is rejected, then $y_{1 t}$ has relation to $y_{2 t}$.

\section{Results and discussion}

\subsection{Data description}

Volatility of VN-Index between Jan. 5, 2006 and March 31, 2014 (Figure 1) is examined to find out the tendency of data variation. Particularly, HNI is more highly volatile than VNI while changes of indexes in recent years tend to be less significant. Exchange rate (EXR) and overnight rate (ITR) reveal profound changes in the period 
2010-2011 and from mid-2012. These volatilities result from SBV's flexible adjustments to the monetary policy in an effort to balance interest and exchange rates for stabilizing economic development (SBV, 2014).

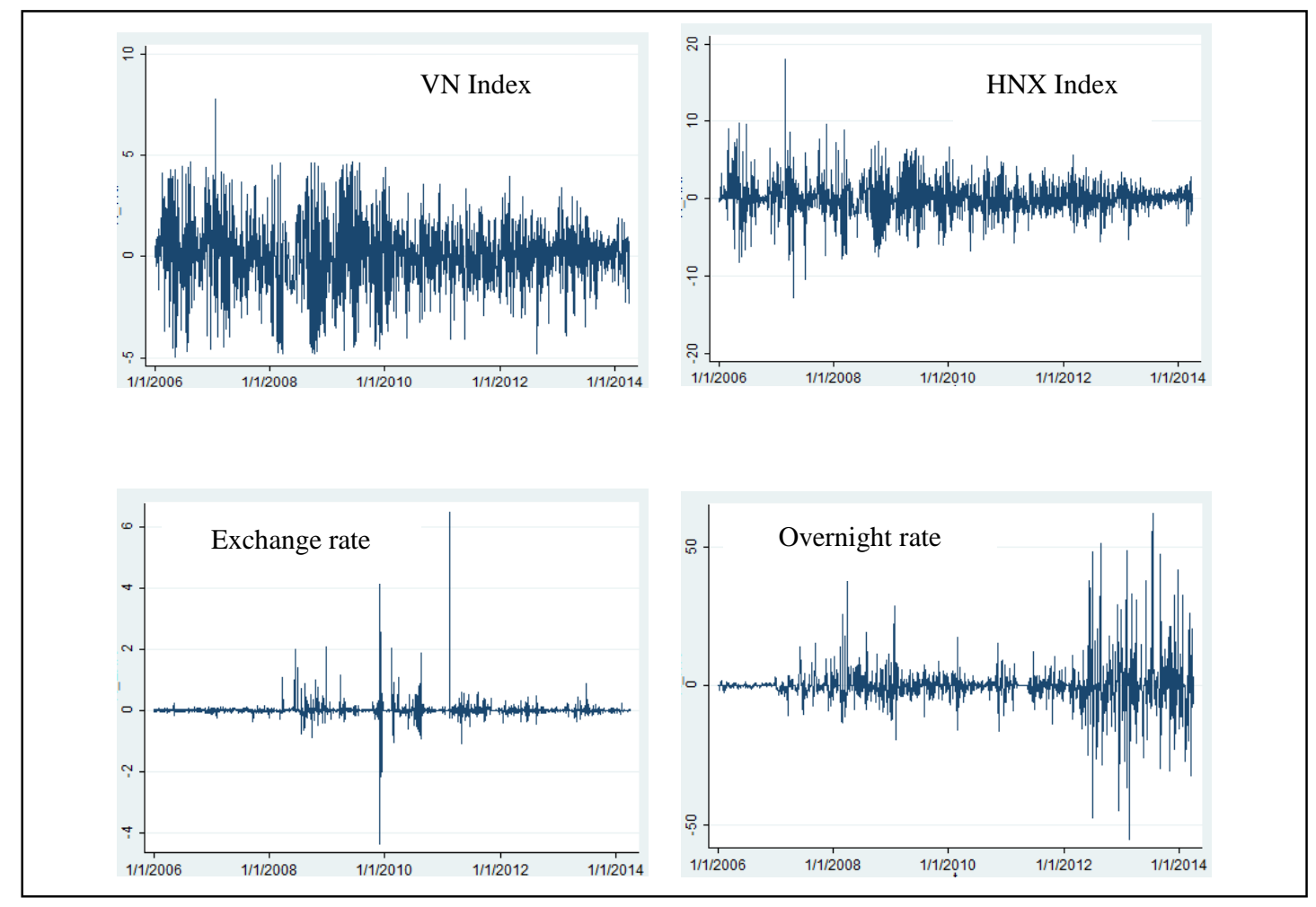

Fig. 1. Volatility of Returns by Indexes

The descriptive statistics presented in Table 1 indicate that daily returns of HNXIndex (R_HNI) are more volatile than those of VN-Index (R_VNI). In addition, among the studied variables, exchange rate (R_EXR) poses the lowest risk, whereas interest rate (R_ITR), the highest risk. The Skewness and Kurtosis indexes imply that only volatility of VNI returns follows normal distribution while the distribution of others is perceived to be right-skewed. 


\section{Table 1}

Descriptive statistics of R_VNI and R_HNI

\begin{tabular}{lllll}
\hline & R_VNI & R_HNI & R_EXR & R_ITR \\
\hline Obs. & 2,136 & 2,136 & 2,136 & 2,136 \\
Mean & 0.03 & 0.00 & 0.01 & -0.08 \\
Std. Dev. & 1.68 & 2.21 & 0.28 & 7.02 \\
Min & -4.96 & -12.89 & -4.36 & -54.91 \\
Max & 7.74 & 18.04 & 6.51 & 62.05 \\
Skewness & -0.06 & 0.25 & 8.02 & 1.25 \\
Kurtosis & 3.79 & 7.78 & 224.58 & 20.76 \\
\hline
\end{tabular}

There are quite many different methods applied to the stationarity test on time series data, yet to avoid spurious regression by conducting the stationarity test, the authors employ those proposed by Dickey and Fuller (1979), Phillips and Person (1988), and Kwiatkowski et al. (1992). The results show that all four time series are non-stationary for the indexes but stationary for the first-order difference at the 5\% significance level (Table 2), based on which regression estimation can be applied to the variables R_VNI, R_HNI, R_EXR, and R_ITR.

\section{Table 2}

Results of stationarity test on data series

\begin{tabular}{lcccccc}
\hline \multirow{2}{*}{ Variable } & \multicolumn{3}{c}{ Index } & \multicolumn{3}{c}{ Returns } \\
\cline { 2 - 7 } & ADF & PP & KPSS & ADF & PP & KPSS \\
\hline VNI & -1.41 & -1.66 & $5.80^{*}$ & $-35.63^{*}$ & $-35.98^{*}$ & 0.20 \\
HNI & -1.17 & -1.38 & $14.50^{*}$ & $-39.30^{*}$ & $-39.74^{*}$ & 0.25 \\
EXR & -0.65 & -0.56 & $23.40^{*}$ & $-54.15^{*}$ & $-54.91^{*}$ & 0.17 \\
ITR & -2.03 & -2.56 & $2.90^{*}$ & $-31.20^{*}$ & $-30.64^{*}$ & 0.05 \\
\hline
\end{tabular}

* denotes sig. at $5 \%$ level

4.2. Results of stock market return volatility 
Prior to the application of GARCH to determine volatilities of the variables, the study conducts Lagrange Multiplier Test, whose results reveal a heteroskedasticity problem in $\mathrm{ARCH} / \mathrm{GATCH}$ at the significance level of $5 \%$ for all variables. Hence, measurement of volatilities can accordingly be performed. Results of Table 3 indicate that all constants of ARCH/GARCH adopt positive values and that the sum of both coefficients is smaller than 1 . These results satisfy prerequisites of the model. Returns of the four data series collected in the study, for this reason, reveal conditional volatility.

\section{Table 3}

Results of volatility of variables

\begin{tabular}{lcccccccc}
\hline & \multicolumn{2}{c}{ R_VNI } & \multicolumn{2}{c}{ R_HNI } & \multicolumn{2}{c}{ R_EXR } & \multicolumn{2}{c}{ R_ITR } \\
\cline { 2 - 9 } & Coef. & p-value & Coef. & p-value & Coef. & p-value & Coef. & p-value \\
\hline ARCH & 0.177 & 0.000 & 0.078 & 0.000 & 0.830 & 0.000 & 0.267 & 0.000 \\
GARCH & 0.787 & 0.000 & 0.920 & 0.000 & 0.119 & 0.000 & 0.720 & 0.000 \\
Constant & 0.105 & 0.000 & 0.018 & 0.001 & 0.015 & 0.000 & 0.009 & 0.000 \\
\hline
\end{tabular}

It is well worth noting that collected coefficients of GARCH, as suggested by the results, are greater than those of ARCH concerning R_VNI, R_HNI and R_ITR, which implies that volatility of returns depends more on past information than on present one. Furthermore, the fact that R_EXR reveals ARCH coefficient higher than GARCH coefficient implies that past information exerts little effects on volatility of exchange rate due to its being rather strictly controlled by SBV via manipulation of exchange rate variance.

4.3. Results of the relationship between volatilities of Vietnam stock market and instruments of monetary policy

To examine the relationship between the volatilities, vector autoregressive model (VAR) is accordingly used. The results of data series tests suggest a stationary model; hence, the variables included in the model comprise volatilities of exchange rate (V_EXR), interest rate (V_ITR), VNI (V_VNI), and HNI (V_HNI). These conditional volatilities are extracted from the aforementioned equations. The relevant tests reveal no cointegration and therefore VAR can be employed. Selection of optimal lag value for the VAR model is based on min of AIC, SIC, and HQ; resulting in an optimum lag of 4. 
The study, therefore, employed VAR with lag-4 for the volatilities; the results are presented in Table 4.

\section{Table 4}

Estimation results of VAR

\begin{tabular}{|c|c|c|c|}
\hline & Coef. & Std. Dev. & Prob. \\
\hline \multicolumn{4}{|c|}{ Determinants of HNI Volatility } \\
\hline V_VNI.L1 & 0.201 & 0.030 & $0.000 *$ \\
\hline V_VNI.L2 & -0.124 & 0.041 & $0.003 *$ \\
\hline V_VNI.L3 & 0.101 & 0.041 & $0.015^{*}$ \\
\hline V_VNI.L4 & -0.096 & 0.030 & $0.001^{*}$ \\
\hline V_HNI.L1 & 0.941 & 0.024 & $0.000 *$ \\
\hline V_HNI.L2 & -0.124 & 0.032 & $0.044^{*}$ \\
\hline V_HNI.L3 & 0.101 & 0.032 & $0.002 *$ \\
\hline V_HNI.L4 & -0.096 & 0.023 & $0.047 *$ \\
\hline V_EXR.L1 & -0.000 & 0.004 & 0.868 \\
\hline V_EXR.L2 & -0.002 & 0.004 & 0.583 \\
\hline V_EXR.L3 & -0.002 & 0.004 & 0.700 \\
\hline V_EXR.L4 & 0.003 & 0.004 & 0.449 \\
\hline V_ITR.L1 & 0.001 & 0.003 & 0.681 \\
\hline V_ITR.L2 & -0.001 & 0.005 & 0.792 \\
\hline V_ITR.L3 & 0.002 & 0.005 & 0.695 \\
\hline V_ITR.L4 & 0.003 & 0.003 & 0.408 \\
\hline Constant & 0.038 & 0.037 & 0.310 \\
\hline \multicolumn{4}{|c|}{ Determinants of VNI Volatility } \\
\hline V_VNI.L1 & 1.009 & 0.023 & $0.000 *$ \\
\hline V_VNI.L2 & -0.089 & 0.033 & $0.007 *$ \\
\hline V_VNI.L3 & 0.021 & 0.033 & 0.522 \\
\hline
\end{tabular}


Table 4 (continued)

\begin{tabular}{llll}
\hline & Coef. & Std. Dev. & Prob. \\
\hline V_VNI.L4 & -0.006 & 0.024 & 0.792 \\
V_HNI.L1 & 0.027 & 0.019 & 0.154 \\
V_HNI.L2 & -0.026 & 0.026 & 0.299 \\
V_HNI.L3 & -0.049 & 0.026 & $0.056^{*}$ \\
V_HNI.L4 & 0.055 & 0.018 & $0.003^{*}$ \\
V_EXR.L1 & 0.000 & 0.003 & 0.832 \\
V_EXR.L2 & 0.002 & 0.003 & 0.479 \\
V_EXR.L3 & 0.002 & 0.003 & 0.513 \\
V_EXR.L4 & 0.001 & 0.003 & 0.591 \\
V_ITR.L1 & 0.000 & 0.002 & 0.920 \\
V_ITR.L2 & -0.000 & 0.004 & 0.865 \\
V_ITR.L3 & -0.002 & 0.004 & 0.886 \\
V_ITR.L4 & 0.000 & 0.002 & 0.255 \\
Constant & 0.166 & 0.030 & $0.000^{*}$ \\
\hline
\end{tabular}

Note: * denotes sig. at $10 \%$ level; L1, L2, L3, and L4 denote the data lags.

The above results demonstrate that the volatilities of Vietnam Stock indexes only depend on their own volatilities at various lags and constants. Precisely, the volatility of VNI is only affected by that of itself for lag-1 and -2 and HNI, lag-3 and -4. In addition, volatility of HNI is under the impact of both HNI and VNI for four of the considered lags. The volatility of monetary policy instruments (overnight rate and exchange rate) has no effect on that of stock market. Based on the test results achieved from VAR model, tests for residual autocorrelation and model stability are conducted. The results indicate that no autocorrelation of residuals at all lag orders is found and that the stability of the model is confirmed because all values remain within the unit circle (Table 5 and Figure 2). 


\section{Table 5}

Results of residual autocorrelation

\begin{tabular}{llll}
\hline Lag & Chi2 & df & Prob > chi2 \\
\hline 1 & 6.8744 & 9 & 0.6502 \\
2 & 11.3292 & 9 & 0.25382 \\
3 & 2.3771 & 9 & 0.98401 \\
4 & 8.267 & 9 & 0.50748 \\
\hline
\end{tabular}

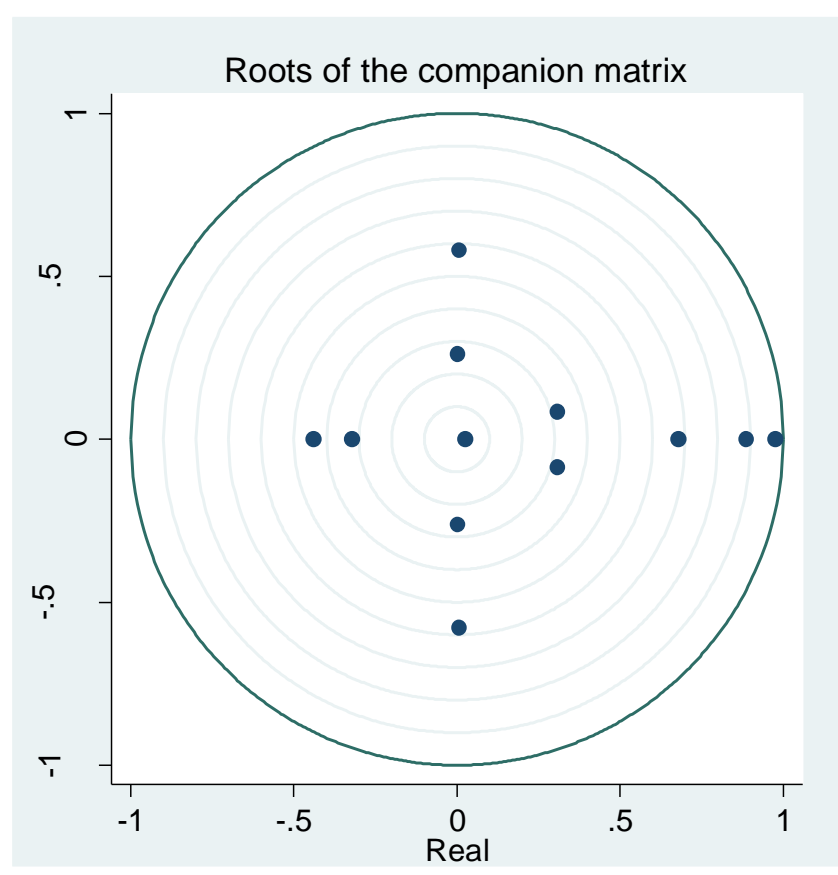

Fig. 2. Test of Model Stability

In brief, it appears that the volatility of stock market depends more on its past volatilities than on those of monetary policy instruments, and the leading role is confirmed for VNI rather than HNI. The results would not be fascinating due to the fact that no relationship between monetary policy and stock market returns has been detected by numerous previous studies, as in Hayford and Malliaris (2004) or Mishkin and White 
(2002). These, however, are significant in examining volatility of stock market for emerging economies.

\section{Conclusions and policy recommendations}

\subsection{Conclusions}

The paper has presented the relationship between volatilities of the two indexes ( VNIndex and HNX-Index) and instruments of monetary policy (overnight rate and USD/VND exchange rate) in the period between Jan. 1, 2006 and March 31, 2014. The results confirm the evidence of volatilities of both indexes based on $\operatorname{GARCH}(1,1)$, and those of VN-Index, HNX-Index and overnight rate ITR, in particular, are affected more by past market information than by the present one. On the contrary, the volatility of exchange rate depends more on the latter, which indicates the discrepancy in determining the volatilities of the studied variables.

Given the nexus between volatilities of Vietnam stock market and instruments of monetary policy, according to VAR model, volatilities of Vietnam stock market depend more on their own lags than on volatilities of the instruments. In addition to the existing relationship between the volatilities of the two indexes, this demonstrates a connection between the two stock markets in Vietnam and confirms the leading role of VN-Index rather than HNX-Index. These results provide detailed insights into the market for relevant authorities, and individual and institutional investors, who should then implement strategies to increase the stability and efficiency in controlling stock market operations.

\subsection{Policy recommendations}

Aiming to examine the volatility of Vietnam stock market through its determinants, the study implies that market authorities in their control of the volatility should well consider the policies on regulation of market operations rather than the State's instruments of monetary policy (particularly, overnight and exchange rates). Hence, their joint efforts should aim at the following issues:

- Improving the legal framework for disclosure of information: The stock market is very sensitive because not only macroeconomic information but also the one revealed by listed enterprises that affect investors' decisions and the market volatility. 
- Enhancing monitoring capacity of market authorities: This proves essential in controlling market volatility and ensuring transparent, efficient and secure operations of the market.

- Conducting further research into the legal framework for market supervision to suggest adjustments to regulations on transactions: Special emphasis could be put on the delegation of responsibilities in implementing supervision of transactions to enhance the quality of market operations.

- Modernizing information technology system: Necessary software programs could be applied to give early warning or detect signs of violations of regulations, thereby building a sound system in line with international practices.

- Market authorities, especially SBV, should flexibly implement the monetary policy based on signals from the market to improve predictions of stock market volatility via instruments of monetary policy and foster transparent, open, adequate and immediate disclosure of information about the instruments, which produces more accurate and reliable results about the relationship between stock market and the instruments.

\subsection{Suggestions for future researches}

Quite a few limitations are revealed concerning the study. First, to measure the extent of volatilities and the impact of overnight and exchange rates on the volatilities, this study basically applies GARCH $(1,1)$ and VAR models, whereas other research methods, especially extended-GARCHs, such as IGARCH (Integrated GARCH), MGARCH (Multivariate GARCH) and PGARCH (Power GARCH) have been adopted with success in existing studies on volatilities of various stock markets. Second, the paper, due to certain database constraints, has yet to take full account of such other indicators of monetary policy instruments as money supply, required reserves, or discount rate; thus, future studies, with more diversified data to appropriately apply updated methods, should keenly anticipate further striking findings regarding the volatility of Vietnam stock market

\section{References}

Abdalla, S., \& Winker, P. (2012). Modelling stock market volatility using univariate Garch models: Evidence from Sudan and Egypt. International Journal of Economics and Finance, 4(8), 161-176. 
Al-Raimony, A., \& El-Nader, H. (2012). The sources of stock market volatility in Jordan. International Journal of Economics and Finance, 4(11), 108-121.

Apergis, N., Miller, S., \& Alevizopoulou, E. (2012). The bank lending channel and monetary policy rules: Further extensions. Procedia Economics and Finance, 2, 63-72.

Ashok, B., \& Sarkar, S. (2006). Modeling daily volatility of the Indian stock market using intra-day data (WPS No. 588). Kolkata, India: Indian Institute of Management Calcutta.

Berument, H. (2007). Measuring monetary policy for a small open economy: Turkey. Journal of Macroeconomics, 29(2), 411-430.

Bhattacharyya, I., \& Sensarma, R. (2008). How effective are monetary policy signals in India? Journal of Policy Modeling, 30(1), 169-183.

Bollerslev, T. (1986). Generalized autoregressive conditional heteroskedasticity. Journal of Econometrics, 31(3), 307-327.

Bui, K. Y., \& Nguyen, T. S. (2014). Development of Vietnam's stock market with effects from macroeconomic factors (in Vietnamese). Journal of Development and Integration, 16(26), 3-10.

Cachanosky, N. (2014). The effects of U.S. monetary policy on Colombia and Panama (2002-2007). The Quarterly Review of Economics and Finance, 54(3), 428-436.

CafeF. (2014). Stock market in 2013 and figures (in Vietnamese). Retrieved February 14, 2012, from http://cafef.vn/thi-truong-chung-khoan/thi-truong-chung-khoan-nam-2013-va-cac-con-so201401021607595036ca31.chn

Cukierman, A. (2013). Monetary policy and institutions before, during, and after the global financial crisis. Journal of Financial Stability, 9(3), 373-384.

de Santis, G., \& Imrohoroglu, S. (1997). Stock returns and volatility in emerging financial markets. Journal of International Money and Finance, 16(4), 561-579.

Dickey, D., \& Fuller, W. (1979). Distribution of the estimators for autoregressive time series with a unit root. Journal of the American Statistical Association, 74(366), 427-431.

Engle, R. (1982). Autoregressive conditional heteroscedasticity with estimates of the variance of United Kingdom inflation. Econometrica, 50(4), 987-1007.

Engle, R., \& Granger, C. (1987). Co-integration and error correction: Representation, estimation, and testing. Econometrica, 55(2), 251-276.

Fernández-Amador, O., Gächter, M., Larch, M., \& Peter, G. (2013). Does monetary policy determine stock market liquidity? New evidence from the Euro Zone. Journal of Empirical Finance, 21, 5468.

Fischbacher, U., Hens, T., \& Zeisberger, S. (2013). The impact of monetary policy on stock market bubbles and trading behavior: Evidence from the lab. Journal of Economic Dynamics and Control, 37(10), 2104-2122. 
Fratzscher, M. (2005). Strategies of exchange rate policy in G3 economies. Economics Letters, 89(1), 68-74.

Garman, M., \& Klass, M. (1980). On the estimation of security price volatilities from historical data. Journal of Business, 53(1), 67-78.

Gokcan, S. (2000). Forecasting volatility of emerging stock markets: Linear versus non-linear Garch models. Journal of Forecasting, 19(6): 499-504.

Hayford, M., \& Malliaris, A. (2004). Monetary policy and the U.S. stock market. Economic Inquiry, 42(3), 387-401.

Hussin, M., Muhammad, F., Abu, M., \& Awang, S. (2012). Macroeconomic variables and Malaysian Islamic stock market: A time series analysis. Journal of Business Studies Quarterly, 3(4), 1-13.

Jansen, D., \& Tsai, C. -L. (2010). Monetary policy and stock returns: Financing constraints and asymmetries in bull and bear markets. Journal of Empirical Finance, 17(5), 981-990.

Johansen, S. (1988). Statistical analysis of cointegration vectors. Journal of Economic Dynamics and Control, 12(2-3), 231-254.

Kwiatkowski, D., Phillips, P., Schmidt, P., \& Shin, Y. (1992). Testing the null hypothesis of stationarity against the alternative of a unit root: How sure are we that economic time series have a unit root? Journal of Econometrics, 54(1-3), 159-178.

Laopodis, N. (2013). Monetary policy and stock market dynamics across monetary regimes. Journal of International Money and Finance, 33(0): 381-406.

Liljeblom, E., \& Stenius, M. (1997). Macroeconomic volatility and stock market volatility: Empirical evidence on Finnish data. Applied Financial Economics, 7(4), 419-426.

Mishkin, F., \& White, E. (2002). U.S. stock market crashes and their aftermath: Implications for monetary policy (NBER Working Paper No. 8992). Retrieved January 26, 2013, from http://www.nber.org/papers/w8992

Pagan, A., \& Schwert, G. (1990). Alternative models for conditional stock volatility. Journal of Econometrics, 45(1-2), 267-290.

Parkinson, M. (1980). The extreme value method for estimating the variance of the rate of return. Journal of Business, 53(1), 61-65.

Phillips, P., \& Person, P. (1988). Testing for a unit root in time series regression. Biometrika, 75(2), 335-346.

Rousan, R., \& Al-Khouri, R. (2005). Modeling market volatility in emerging markets in the case of daily data in Amman stock exchange 1992-2004. International Journal of Applied Econometrics and Quantitative Studies, 2(4), 100-118.

Schwert, G. (1989). Why does stock market volatility change over time? Journal of Finance, 44(5), 1115-1153.

Sims, C. A. (1980). Macroeconomics and reality. Econometrica, 48(1), 1-48. 
Tang, Y., Luo, Y., Xiong, J., Zhao, F., \& Zhang, Y. (2013). Impact of monetary policy changes on the Chinese monetary and stock markets. Physica A: Statistical Mechanics and its Applications, 392(19), 4435-4449.

Vietnam National Assembly. (2010). The state bank of Vietnam law (in Vietnamese). Retrieved October 13 , 2013 from http://vanban.chinhphu.vn/portal/page/portal/chinhphu/hethongvanban?class_id=1\&mode=detail \&document_id=96040

Vietnam-Russia Bank. (2014). Changes in interest rate and exchange rate viewed from managerial point (in Vietnamese). Retrieved March 15, 2013 from http://www.vrbank.com.vn/NewsShow1.aspx?id=283\&lang=vn

Vithessonthi, C., \& Techarongrojwong, Y. (2013). Do monetary policy announcements affect stock prices in emerging market countries? The case of Thailand. Journal of Multinational Financial Management, 23(5), 446-469.

Xu, J. (1999). Modeling Shanghai stock market volatility. Annals of Operations Research, 87, 141152.

Zakaria, Z., \& Shamsuddin, S. (2012). Empirical evidence on the relationship between stock market volatility and macroeconomics volatility in Malaysia. Journal of Business Studies Quarterly, 4(2), 61-71. 